\title{
Pronominal Determiners in Gerundive Nominalization: A "Case" Study
} Liesbet Heyvaert, Hella Rogiers and Nadine Vermeylen

\section{Introduction}

This paper concerns itself with a subtype of -ing nominalizations and, in particular, with the case for which its pronominal determiners are marked. The -ing nominals that will be looked at belong to Lees's category of "gerundive nominals." -ing nominals of the gerundive type distinguish themselves from so-called "action" -ing nominals in a number of ways: they can take auxiliaries of secondary tense (e.g. "... there was no sign of [him having been home] ..." $\left.(\mathrm{CB})^{2}\right)$, and of the passive voice (e.g. "A serious pull would almost certainly lead to [him being replaced] ..." (CB)); they are modified by adverbials rather than by adjectives (e.g. gerundive his drawing the picture rapidly vs. action nominal his rapid drawing of the picture), ${ }^{3}$ and instead of realizing their objects periphrastically (by means of an of- phrase), they construe them in a clause-like manner (e.g. " . . the prospect of [their joining the EU] was very distant ..." (CB)). While action nominals come close to ordinary noun phrases, the internal structure of gerundive nominalizations is thus in many ways more clause-like in nature.

In spite of their overall clause-like nature, gerundive nominals can be construed with the "subject" of the nominalized process in the genitive case:

(1) Of course, I know the answer and worry that my posing the question defines me as a depressive or as middle aged or both. (CB)

(2) Some researchers have felt that having a mental illness would lead to the individual's occupying a position in a lower social class ... (CB)

This genitive/possessive is probably the most visible remnant of the origin of modern gerundive nominalizations: together with action -ing nominals (e.g. John's signing of

Liesbet Heyvaert, Hella Rogiers and Nadine Vermeylen are affiliated with the University of Leuven, Belgium. Liesbet Heyvaert is a postdoctoral researcher of the Fund for Scientific Research - Flanders.

${ }^{1}$ Lees, English Nominalizations, 71.

${ }^{2}$ Our data were extracted from the COBUILD corpus (henceforth 'CB') via remote log-in. They are reproduced here with kind permission of HarperCollins Publishers.

${ }^{3}$ Lees, English Nominalizations, 66. 
the contract; his sending of the letter), gerundives can be traced back to an Old English derivative in -ing which functioned as a full noun. ${ }^{4}$ Action nominals have preserved most of the latter's nominal properties, still taking nominal determiners other than the genitive/possessive (e.g. "... when it comes to [the awarding of contracts] ..." (CB); "During July we noticed [a browning of our cherry tree leaves ..." (CB)). By contrast, in gerundive nominals, the genitive is the only nominal means of determination left: gerundives preceded by articles (such as those in (3) and (4)) have been stigmatized as "nonstandard" by prescriptive grammars from the eighteenth century onwards ${ }^{5}$ and have by now become definitely ungrammatical: ${ }^{6}$

(3) The great art of poets is either the adorning and beautifying of truth, or the inventing pleasing and probable fictions. (Dryden $1674^{7}$ )

(4) Master Blifil objected to the sending away the servant. (Fielding ${ }^{8}$ )

Interestingly, the subject preceding the -ing form in gerundive nominals cannot only be marked for the genitive: it can also take the oblique (in the case of pronouns) or the common case (i.e. when it is a noun):

(5) ... their temperament is either partly responsible for them getting the disease, or is unlikely to aid them in fighting it. (CB)

(6) Albrecht believes lies were circulated about him being racist. (CB)

(7) As matters stand, Tory MPs who resent John Major outmanoeuvring them in last year's leadership coup will always find journalists more than willing to indulge their conspirational ambitions. (CB)

(8) I am a great believer in the body being able to heal itself. (CB)

The occurrence of non-genitive case-marking in gerundive nominalizations has been viewed as an indication that "the construction of the ing has approached that of verbs in one more point." Not surprisingly, the non-genitive case is not found in -ing nominalizations with a more nominal internal character such as action nominals (e.g. “... [his/Getty's amassing of artefacts] was so great that an imperial Roman villa was

\footnotetext{
${ }^{4}$ Visser, An Historical Syntax, 1065.

${ }^{5}$ Described in Jespersen, A Modern English Grammar; Visser, An Historical Syntax, 1210-12.

${ }^{6}$ The demonstratives this and that and the quantifiers no and any, on the other hand, are still used, but then in marginal constructions such as the following: (a) This burning the midnight oil of yours has got to stop. (Schachter, "Gerundive nominals in English," 218); (b) Any talking loudly on your part will be punished. (Schachter 1976: 218); (c) There'll be no stopping her. (Huddleston and Pullum, The Cambridge Grammar, 1189).

${ }^{7}$ Quoted in Visser, An Historical Syntax, 1210.

${ }^{8}$ Quoted in Jespersen, A Modern English Grammar, 119.

${ }^{9}$ Jespersen, A Modern English Grammar, 122; see also Huddleston and Pullum, The Cambridge Grammar, 118990. It can be pointed out here, however, that, as Visser shows in An Historical Syntax, 1172-7, the use of the non-genitive case in gerundive nominals does not come out of the blue and can be traced back to Old English. It may, in other words, not be as innovative and recent as some grammarians seem to suggest.
} 
built in California ..." (CB) but not "*[him/Getty amassing of artefacts] was so great that ...").

Gerundive nominalizations with oblique or common case have long been rejected as "grossly ungrammatical"10 and "due to mere slovenliness."11 In fact, as Huddleston and Pullum ${ }^{12}$ point out, modern grammars still "vary in their tolerance of them, the more conservative ones advocating a genitive except where it sounds awkward, stilted, or pedantic - by virtue of the type of NP involved." In practice, the only noun phrases that are used in the genitive in gerundive nominalizations are "singular NPs that refer to people and have no more than one or two words as prehead dependents." ${ }^{13}$ Gerundive nominalizations in which the word preceding the gerund is a personal pronoun, by contrast, seem to have undergone the influence of prescriptive grammar-with its preference for the genitive-more strongly than gerundive nominals with NPs in first position. It has, for instance, been pointed out in the literature that pronouns in the oblique case occur primarily in dialect speech and in ordinary colloquial English. ${ }^{14}$ In 1929, Poutsma ${ }^{15}$ wrote that "the construction with the objective of a personal pronoun is not nearly so frequent as that with a possessive pronoun. In literary English, it is, in fact, distinctly unusual." More recently, Quirk et al. ${ }^{16}$ have posited that "the genitive is preferred if the item is a pronoun ... and the style is formal." Dekeyser et al. ${ }^{17}$ also argue that, even though

\footnotetext{
${ }^{10}$ White, 1904, as cited in Visser An Historical Syntax, 1183.

${ }^{11}$ Bain 1904, as cited in Visser, An Historical Syntax, 1178.

${ }^{12}$ Huddleston and Pullum, The Cambridge Grammar, 1192.

${ }^{13}$ Huddleston and Pullum, The Cambridge Grammar, 1193. The list of NPs that do not take the genitive in gerundive nominals is extensive: one tends to avoid the genitive with nouns denoting abstract or inanimate notions (e.g. surprised at her beauty being made so much of, Jespersen, A Modern English Grammar, 130), with singular nouns ending in -s (e.g. grace, Nicholas, police, Visser, An Historical Syntax, 1181; The jealousy of his contemporaries prevented justice being done to him during his lifetime, Poutsma, A Grammar of Late Modern English, 833), with plural nouns ending in -s (e.g. the girls being given preferential treatment, Huddleston and Pullum, The Cambridge Grammar, 1192); with more complex units (e.g. the Minister of Transport losing face, Huddleston and Pullum, The Cambridge Grammar, 1192); and, finally, when a phrase or adverbial intervenes between the noun and the form in -ing (e.g. any Home Rule Bill which may pass Parliament being submitted to a poll of the people, Poutsma, A Grammar of Late Modern English, 836; Trafford very rapidly and easily coming forward into a position of cardinal significance, Jespersen, A Modern English Grammar, 131).

${ }^{14}$ See, for instance, Lees, English Nominalizations; Stannard Allen 1947, as cited in Visser, An Historical Syntax, 1183; Dekeyser et al., Foundations of English Grammar, 293; Downing and Locke, A University Course in English Grammar, 35). In gerundives with indefinite pronouns (anyone, anybody), with the "dummy" pronoun there and with quantifiers such as all, both, each, the non-genitive case is used as well, and this is because the genitive is just not available (for a more extensive treatment of the restrictions that exist on using the genitive in gerundive nominalization, see Poutsma, A Grammar of Late Modern English, 833-7; Jespersen, A Modern English Grammar, 123 -9; Visser, An Historical Syntax, 1181; Huddleston and Pullum, The Cambridge Grammar, 1192 3): (a) It's a thousand to one against anybody's finding it out by accident. (Poutsma, A Grammar of Late Modern English, 834) (b) He resented there/*there's having been so much publicity. (Huddleston and Pullum, The Cambridge Grammar, 1192) (c) ... the no small risk of both falling out of the blanket. (Visser, An Historical Syntax, 1182) (d) The happiness of both [sexes] depends on each asking and receiving from the other what the other only can give. (Jespersen, A Modern English Grammar, 125).

${ }^{15}$ Poutsma, A Grammar of Late Modern English, 835.

${ }^{16}$ Quirk et al., A Comprehensive Grammar, 1063.

${ }^{17}$ Dekeyser et al., Foundations of English Grammar, 294.
} 
the use of the genitive in formal language does not constitute a "rule," it can nonetheless be said to "reflect trends in good present-day usage." Likewise, Declerck ${ }^{18}$ posits that in gerundive nominals, "Formal English uses the genitive/ possessive form; informal English uses the object form." In short, it seems to be generally agreed that gerundives with an oblique pronoun are particularly well established in informal English, while formal English prefers possessive pronouns.

In this paper, we want to confront these observations concerning the use of personal pronouns in gerundive nominalizations with a detailed analysis of gerundive nominalizations as they occur in the COBUILD corpus (i.e. the Bank of English). The questions that we will be addressing are the following:

- Does formal language prefer gerundive nominals with personal pronouns marked for the genitive/possessive to gerundive nominals with an oblique pronoun?

- Do oblique pronouns form a majority in gerundive nominalizations in informal language?

Or: has prescriptive grammar succeeded in branding the oblique form as informal and are modern descriptive grammars such as Quirk et al. ${ }^{19}$ and Dekeyser et al. ${ }^{20}$ right in saying that, in gerundive nominalizations in formal language, possessive pronouns are preferred to pronouns in the oblique?

\section{Gerundive Nominalizations in the COBUILD Corpus}

To determine how far the use of personal pronouns in gerundive nominals is register-bound, we examined corpus data from two subcorpora of the Collins COBUILD corpus. We extracted material from the Times corpus, which is a corpus of 5,763,761 words based on the newspaper The Times. The written, highly formal register which it represents allowed us to check on the claim that possessive pronouns are preferred in formal language. To see whether oblique pronouns predominate in informal language, then, we extracted data from the UKspoken corpus, a collection of 9,272,579 words based on recordings of informal speech. From both corpora, all instances of the pattern PRONOUN + VBG (i.e. verb in -ing form) were extracted and classified. The personal pronouns we searched for were those with a distinct form for the genitive and the oblique, i.e. I, you, he, they, we and it (the pronoun she has her for the genitive as well as for the oblique and has therefore not been taken into account): the genitive forms of these pronouns are my, your, his, their, our and its; their oblique counterparts are me, you, him, them, us and it.

\footnotetext{
${ }^{18}$ Declerck, A Comprehensive Descriptive Grammer, 499.

${ }^{19}$ Quirk et al., A Comprehensive Grammar.

${ }^{20}$ Dekeyser et al., Foundations of English Grammar.
} 
Of the data that we acquired through these searches, we left out a number of incomprehensible structures (especially data extracted from the UKspoken corpus, as in (9) and (10)) and we eliminated structures in which the (oblique) pronoun does not function as determiner of the gerund (see (11), (12), (13), and (14)):

(9) You you $<\mathrm{ZF0}>$ you realise that an opportunity cost your using your endowments at home self-financed investment because there's another way of making money. (UKspoken)

(10) Well because we borrow the money $<\mathrm{tc}$ text=cough $>$ we increase our borrowing a debt and the increase in our foreign debt makes foreigners less enthusiastic about lending to us next year ... (UKspoken)

(11) What's it done for you seeing your sister healed like this? (UKspoken) [gerundive nominalization without determiner]

(12) Afterwards, with them standing silently beside him at a press conference, he announced that some form of national preference for French people would be put into action after all. (Times) [non-finite clause]

(13) ... cos they was coming up to me saying Still going out with him? (UKspoken) [non-finite clause]

(14) Erm so he can get he can often get the staff against him doing exactly the same thing as FX is doing ... (UKspoken) [non-finite clause]

In addition, we removed those structures that contained a non-verbal -ing form (e.g. adjectival as in (15) or nominal as in (16)), as well as ambiguous -ing constructions (as in (17) and (18)). The latter are structures of which the verbal status could not be determined because the -ing form was preceded by a possessive pronoun, was not followed by an object or an adverbial and did not include auxiliaries: $^{21}$ structures like these can be either gerundive nominals or action nominalizations centred on a deverbal noun (see above).

(15) They're somehow making sensible er inferences on the basis of their underlying cognitive capacities ... (UKspoken)

(16) ... he gave me a privileged glimpse of preparations for Wednesday's match by inviting me into his working office beneath the Ibrox stands an hour before kick-off. (Times)

(17) "It was another excellent clean sheet for Mark," Clark said. "His kicking might have been a bit off but his job is to keep the ball out of the net and he did that brilliantly." (Times)

(18) Dettori has not only captivated the racing world but transcended it. It is his charisma and showmanship that have launched the Dettori story into orbit at least as much as his riding. (Times)

\footnotetext{
${ }^{21}$ See also Quirk et al., A Comprehensive Grammar, 1065.
} 
Finally, we left out all -ing structures that followed verbs of perception (e.g. see, hear, feel, watch) because rather than offering the choice between possessive and oblique case, they necessarily take oblique determiners: ${ }^{22}$

(19) Have you heard us playing the stories from that? (UKspoken)

(20) We know these people are fallible, so we want to know about their lives, their conversations, their methods of working, rather than just watch them catching the villains. (Times)

In all, we thus compiled a set of 1,050 gerundive nominalizations, 831 of which were extracted from the UKspoken corpus of COBUILD, and 219 from the Times corpus. In 911 instances, the subject was realized by an oblique pronoun; the remaining 139 gerundive nominals contained a pronoun in the genitive case. To find out whether correlations exist between the use of oblique or possessive case and the function that is served by the gerundive nominal, we classified all gerundive nominals not only according to the case for which their pronominal determiners were marked, but also according to the function which they served in the clause. We thereby distinguished between gerundive nominals functioning as direct object (as in (21) and (22)); as subject (either with or without anticipatory it, see (23) and (24)); as subject complement in copular clauses (illustrated in (25)); and, finally, as prepositional complement. Among the gerundive nominals preceded by a preposition, we further differentiated between gerundive nominals functioning as prepositional complement of a verb (see (26) and (27)) or an adjective (as in (28)); gerundive nominals functioning as postmodifier to a noun (as in (29)); and, finally, gerundive nominals figuring in prepositional phrases with adjunct function (as in (30) and (31)):

(21) I don't mind you saying that. (UKspoken)

(22) We're behind you because you're a winner and a champion. Appreciate you being a Cowboy fan, an old boy from Arkansas. (Times)

(23) ... I know the answer and worry that my posing the question defines me as a depressive or as middle aged or both. (Times)

(24) So it's no good you saying they can't do it John. (UKspoken)

(25) ... that's just me getting older and calming down. (Times)

(26) ... he doesn't respond to you playing sort of funny jazz chords ... (UKspoken)

(27) It doesn't fit in with you saying that $y<\mathrm{ZF} 1>$ nothing $<\mathrm{ZF} 0>$ nothing stressful has happened in your life. (UKspoken)

(28) I am very grateful for you sharing that with us. (UKspoken)

\footnotetext{
${ }^{22}$ See, among others, Quirk et al., A Comprehensive Grammar; Huddleston and Pullum, The Cambridge Grammar.
} 
(29) There's more chance of me asking Oliver Reed to babysit than there is of me taking up a once in a lifetime opportunity to buy tableware from a credit card company. (Times)

(30) I tag along, despite him being gloomy about it. (UKspoken)

(31) Another embryo invention comprises a breathing machine that measures a person's fitness simply by them blowing into a tube. (UKspoken)

\section{Results of the Corpus Analysis}

In general, the analysis of the corpus data makes it clear that the use of possessive or oblique case in gerundive nominals is less register bound than has thus far been suggested: oblique pronouns predominate in the informal as well as in the formal register. It does, however, appear to be the case that in formal language one finds relatively more possessives than in informal speech. Our quantitative analysis of the various functions which gerundive nominals serve in larger structures moreover points to interesting correlations between the case for which the pronoun in gerundive nominalizations is marked and the function which the nominal serves. Finally, that the choice for oblique or possessive case is very much a word-by-word process becomes clear when, within one and the same function, significant differences turn out to exist depending on the preposition or matrix verb that is used. In what follows, we will briefly elaborate on each of these findings and point to some of the issues which, our study shows, are in need of further research.

\section{Possessive vs. Oblique: A Matter of Register?}

Table 1 presents an overview of the raw frequency counts of gerundive nominals with oblique and possessive case which we extracted from the UKspoken corpus and the Times corpus. In the rightmost column one finds the total number of gerundive nominalizations with oblique and genitive pronouns found in each corpus.

To find out to what extent possessive or oblique pronouns are used in formal and informal language, we had to make sure that the counts of gerundive nominalizations in the UKspoken corpus and in the Times corpus were comparable. Because the two subcorpora are not of the same length, merely comparing raw frequency counts of them would have led to misleading results. We therefore applied the "normalization"

Table 1 An overview of the distribution of oblique and possessive case in the UKspoken corpus and the Times corpus

\begin{tabular}{lccccccc}
\hline & me/my & you/your & him/his & it/its & us/our & them/their & OBL/GEN \\
\hline UKspok & $177 / 20$ & $187 / 22$ & $102 / 3$ & $119 / 0$ & $60 / 9$ & $122 / 10$ & $767 / 64$ \\
Times & $14 / 7$ & $8 / 2$ & $57 / 29$ & $28 / 6$ & $11 / 11$ & $26 / 20$ & $144 / 75$ \\
\hline
\end{tabular}


procedure suggested in Biber et al. ${ }^{23}$ and divided the frequency counts of gerundive nominals occurring in each subcorpus by the number of words in the corpus, after which we normed the counts in the two corpora to a basis of 100,000 words of text by multiplying by 100,000 . This gave us an idea of the relative frequency with which gerundive nominalizations with pronominal determination in general are used in formal and in informal language:

UKspoken: (831 ger. nom./9.272.579 words $) \times 100,000=8.9619$ per 100,000 words.

Times: (219 ger. nom./5.763.761 words $) \times 100,000=3.7996$ per 100,000 words.

These figures show that the relative frequency of gerundive nominalizations with pronominal determination in general is significantly higher in the UKspoken corpus than in the Times corpus. (It would be interesting to see whether these relative frequencies are confirmed when other types of gerundive nominalizations (e.g. with proper name, common noun; without determiner) are taken into account.) Consider now the relative distribution of oblique and possessive case in the UKspoken and Times corpora:

UKspoken: $(767$ obl./9.272.579 words $) \times 100,000=8.2717$ per 100,000 words.

(64 poss./9.272.579 words $) \times 100,000=0.6902$ per 100,000 words.

Times: $(144 \mathrm{obl} . / 5.763 .761$ words $) \times 100,000=2.4983$ per 100,000 words.

$(75$ poss./5.763.761 words $) \times 100,000=1.3013$ per 100,000 words.

Note that of the gerundive nominalizations with personal pronouns in the UKspoken corpus, gerundives with oblique determiners constitute about 93 per cent (i.e. 767 out of 831), while possessive pronouns are found in only 7 per cent of the attested examples (i.e. in 64 out of 831 cases). In the Times corpus, by contrast, the distribution is 65 percent obliques (i.e. 144 out of 219) versus 35 per cent possessives (i.e. 75 out of 219 ).

What can we conclude from these figures? First of all, it is clear that, in terms of raw counts (see Table 1), gerundives with oblique pronouns form a majority in informal as well as in formal language: both in the UKspoken corpus and in the Times corpus, the number of oblique pronouns far exceeds that of possessives. The questions that were formulated in the introduction, i.e.

(1) does formal language prefer personal pronouns marked for the genitive to pronouns marked for the oblique? and

(2) do oblique pronouns form a majority in informal language?

\footnotetext{
${ }^{23}$ Biber et al., Corpus Linguistics, 263; see also Meyer, English Corpus Linguistics, 126.
} 
can therefore be answered as follows: first, the oblique case is well established in informal language, to the extent that it has practically replaced the possessive. Second, contrary to what has been suggested in the literature, ${ }^{24}$ personal pronouns in the genitive case do not predominate in formal language either: in the formal Times corpus as well, oblique pronouns form a majority. It would, in short, be descriptively inaccurate and (prescriptively) misleading to say that formal language prefers gerundive nominalizations with possessive pronouns.

At the same time, however, the "normed" frequency counts in (33) and the distribution of obliques and possessives in terms of percentages make it clear that the number of gerundive nominals with a possessive pronoun is relatively higher in the formal Times corpus than in the UKspoken corpus. Put differently, if we compare the attested gerundives of the UKspoken corpus with those of the Times corpus, it is in the formal Times corpus that more possessives are used. At most, therefore, possessives can be said to be somewhat more readily used in formal than in informal language. However, it is the oblique case which is predominant in present-day gerundive nominalizations in general.

\section{The Case of Pronouns in Gerundive Nominalization: Also a Matter of Function}

The observation that, while they form a minority in gerundive nominalizations in general, possessive pronouns are more readily used in formal than in informal discourse can be further refined when the various functions of gerundive nominalizations are taken into consideration. In Tables 2 and 3, an overview is given of the frequency with which obliques and possessives occur per function: Table 2 lists the counts of gerundive nominals in the UKspoken corpus; Table 3 does the same for the Times corpus.

Table 2 Raw counts of the oblique and possessive pronouns in the UKspoken corpus

\begin{tabular}{lccrrrrr}
\hline & me/ my & you/ your & him/ his & it/ its & us/ our & them/their & OB/GEN \\
\hline prep. comp. to V & $11 / 4$ & $32 / 6$ & $12 / 0$ & $17 / 0$ & $7 / 2$ & $20 / 2$ & $99 / 14$ \\
object & $47 / 2$ & $50 / 1$ & $42 / 1$ & $25 / 0$ & $9 / 1$ & $36 / 3$ & $209 / 8$ \\
subject & $11 / 2$ & $9 / 2$ & $5 / 0$ & $1 / 0$ & $7 / 2$ & $6 / 1$ & $39 / 7$ \\
subject compl & $35 / 0$ & $7 / 0$ & $3 / 2$ & $0 / 0$ & $1 / 0$ & $3 / 0$ & $49 / 2$ \\
postmod. to Noun & $36 / 7$ & $35 / 7$ & $15 / 0$ & $38 / 0$ & $15 / 2$ & $25 / 2$ & $164 / 18$ \\
adject. phrase & $12 / 1$ & $17 / 1$ & $8 / 0$ & $4 / 0$ & $6 / 1$ & $12 / 1$ & $59 / 4$ \\
prep. phrase, adv. & $25 / 4$ & $37 / 5$ & $17 / 0$ & $34 / 0$ & $15 / 1$ & $20 / 1$ & $148 / 11$ \\
total & $177 / 20$ & $187 / 22$ & $102 / 3$ & $119 / 0$ & $60 / 9$ & $122 / 10$ & $767 / 64$ \\
\hline
\end{tabular}

\footnotetext{
${ }^{24}$ See, among others, Poutsma, A Grammar of Late Modern English, Quirk et al., A Comprehensive Grammar; Dekeyser, Foundations of English Grammar.
} 
Do there exist specific correlations between the function which a gerundive nominal serves and the case which its pronominal determiner is marked for? First, it can be pointed out that when all attested nominals (i.e. those found in the UKspoken corpus as well as those of the Times corpus) are taken into consideration, the proportion of obliques and possessives is more or less the same for all functions, with oblique case figuring in about 80-90 per cent of all attested instances and the possessive in only 10-20 per cent (see Table 4). If, however, the results for the Times corpus are considered separately, four functions turn out to have a ratio of oblique vs. possessive which is fundamentally different from that presented in Table 5 . Compare these figures to the ratio of oblique vs. possessive of these functions in the UKspoken corpus as represented in Table 6.

The figures in Tables 5 and 6 suggest that in formal language and when functioning as prepositional complement to a verb, as clausal subject, as postmodifier to a noun and as a prepositional phrase functioning as adjunct, the chances of a gerundive nominalization taking possessive case are significantly higher than in informal language: instead of a 20 per cent chance of taking possessive case (as in informal language), gerundives in those functions have a chance of around 40 per cent of taking a pronoun in possessive form. If they function as subject, their chances of

Table 3 Raw counts of the oblique and possessive pronouns in the Times Corpus

\begin{tabular}{lccccccc}
\hline & me/ my & you/ your & him/ his & it/ its & us/ our & them/their & OB/GEN \\
\hline prep. comp. to V & $3 / 3$ & $0 / 2$ & $12 / 10$ & $6 / 1$ & $2 / 1$ & $4 / 3$ & $27 / 20$ \\
object & $1 / 1$ & $4 / 0$ & $20 / 2$ & $7 / 0$ & $4 / 1$ & $8 / 5$ & $44 / 9$ \\
subject & $0 / 1$ & $0 / 0$ & $0 / 0$ & $0 / 0$ & $0 / 1$ & $0 / 1$ & $0 / 3$ \\
subject compl & $1 / 0$ & $1 / 0$ & $1 / 1$ & $0 / 0$ & $2 / 1$ & $1 / 0$ & $6 / 2$ \\
postmod. to Noun & $5 / 2$ & $0 / 0$ & $17 / 9$ & $11 / 5$ & $3 / 6$ & $9 / 9$ & $45 / 31$ \\
adject. phrase & $0 / 0$ & $2 / 0$ & $3 / 0$ & $0 / 0$ & $0 / 1$ & $3 / 0$ & $8 / 1$ \\
prep. phrase, adv. & $4 / 0$ & $1 / 0$ & $4 / 7$ & $4 / 0$ & $0 / 0$ & $1 / 2$ & $14 / 9$ \\
total & $14 / 7$ & $8 / 2$ & $57 / 29$ & $28 / 6$ & $11 / 11$ & $26 / 20$ & $144 / 75$ \\
\hline
\end{tabular}

Table 4 An overview of the number of obliques and possessives found for each function in the UKspoken corpus and the Times corpus

\begin{tabular}{llc}
\hline & oblique & possessive \\
\hline prep. comp. to V (160) & $79 \%(126)$ & $21 \%(34)$ \\
object (270) & $94 \%(253)$ & $6 \%(17)$ \\
subject (49) & $80 \%(39)$ & $20 \%(10)$ \\
subject compl. (59) & $93 \%(55)$ & $7 \%(4)$ \\
postmod. to N (258) & $81 \%(209)$ & $19 \%(49)$ \\
prep. comp. to adjective (72) & $93 \%(67)$ & $7 \%(5)$ \\
prep. phrase, adjunct (182) & $89 \%(162)$ & $11 \%(20)$ \\
\hline
\end{tabular}


Table 5 The number of obliques and possessives in specific functions in the Times corpus only

\begin{tabular}{lcc}
\hline & oblique & possessive \\
\hline prep. comp. to V (47) & $57 \%(27)$ & $43 \%(20)$ \\
subject (3) & $0 \%(0)$ & $100 \%(3)$ \\
postmod. to N (76) & $59 \%(45)$ & $41 \%(31)$ \\
prep. phrase, adjunct (23) & $61 \%(14)$ & $39 \%(9)$ \\
\hline
\end{tabular}

Table 6 The number of obliques and possessives in specific functions in the UKspoken corpus only

\begin{tabular}{llc}
\hline & oblique & possessive \\
\hline prep. comp. to V (113) & $88 \%(99)$ & $12 \%(14)$ \\
subject (46) & $85 \%(39)$ & $15 \%(7)$ \\
postmod. to N (182) & $90 \%(164)$ & $10 \%(18)$ \\
prep. phrase, adjunct (159) & $93 \%(148)$ & $7 \%(11)$ \\
\hline
\end{tabular}

taking a possessive case are even higher, witness the ratio of 100 per cent possessives to 0 per cent obliques for gerundive nominals in subject function in the Times corpus. The difference with gerundive nominals in subject function in the UKspoken corpus is striking: only 15 per cent of the gerundive nominals there have a pronominal determiner in the genitive case.

Huddleston and Pullum's ${ }^{25}$ claim that a gerundive nominalization "in subject function is somewhat more likely to select a genitive than one in other complement functions" can thus be refined in two ways: first, gerundive nominals in subject function are only more likely to select a genitive when they are used in formal language; in the informal register, they have an 85 per cent chance of being used with an oblique. Second, the "other complement functions" which Huddleston and Pullum $^{26}$ refer to likewise show considerable variation depending on the register they are used in: in particular, gerundive nominals that are used in formal discourse and function as prepositional complement to a verb, as postmodifier to a noun, or as prepositional adjunct have a chance of around 40 per cent of taking a possessive. When used in informal language, however, these functions take the possessive only around 10 per cent of the time. This is not significantly lower than informally used gerundive nominals in subject function. In formal language, gerundive nominals functioning as subject are, in short, more likely to select a genitive than other

\footnotetext{
${ }^{25}$ Huddleston and Pullum, The Cambridge Grammar, 1193.

${ }^{26}$ Huddleston and Pullum, The Cambridge Grammar, 1193.
} 
complement functions, depending on the type of complement one considers: gerundive nominals functioning as prepositional phrase to a verb, as postmodifier to a noun, and as prepositional adjunct have more chance of taking possessive case than do gerundives functioning as subject complement, object or prepositional phrase following an adjective.

Some other tentative conclusions that can be drawn from the quantitative data in Tables 5 and 6 are the following. First, of the functions that have a stronger preference for the possessive than others when they are used in formal language (see Table 5), that of nominal postmodifier stands out: as can be deduced from Table 7, gerundive nominalizations with postmodifying function are responsible for as much as 41 per cent of the total number of possessives found in the Times corpus.

Structures such as that in (34), in other words, exemplify the most frequently found type of gerundive nominalization with possessive pronominal determiner:

(34) However, he ruled out the prospect of his being passed fit to partner Master Oats in the Hennessy Cognac Irish Gold Cup a week on Sunday. (Times)

There also appears to exist an interesting difference between gerundive nominalizations occurring as direct object of a matrix verb (as in (35)) and those that function as prepositional complement of a verb ( $\mathrm{PP}$ to $\mathrm{V}$ ) (as in (36)) - at least in formal language.

(35) Probably the best thing about Russian women is that they'll never mind you coming home drunk. (Times)

Table 7 Raw counts and percentages of possessive pronouns in the Times Corpus

\begin{tabular}{|c|c|c|c|c|c|c|c|}
\hline & my & your & his & its & our & their & total \\
\hline $\begin{array}{l}\text { prep. comp. to } \\
\text { V }\end{array}$ & (3) $43 \%$ & (2) $100 \%$ & (10)34\% & (1) $17 \%$ & (1) $9 \%$ & (3) $15 \%$ & (20) $27 \%$ \\
\hline object & (1) $14 \%$ & (0) $0 \%$ & (2) $7 \%$ & (0) $\mathbf{0} \%$ & (1) $9 \%$ & (5) $25 \%$ & (9) $12 \%$ \\
\hline subject & (1) $14 \%$ & (0) $0 \%$ & (0) $\mathbf{0 \%}$ & (0) $0 \%$ & (1) $9 \%$ & (1) $5 \%$ & (3) $4 \%$ \\
\hline \multirow[t]{2}{*}{ subject compl } & (0) $\mathbf{0} \%$ & & & & & & \\
\hline & (0) $\mathbf{0} \%$ & (1) $4 \%$ & (0) $\mathbf{0} \%$ & (1) $9 \%$ & (0) $\mathbf{0} \%$ & (2) $3 \%$ & \\
\hline postmod. to & (2) $29 \%$ & (0) $0 \%$ & (9) $31 \%$ & (5) $83 \%$ & (6) $55 \%$ & (9) $45 \%$ & (31) $41 \%$ \\
\hline Noun & & & & & & & \\
\hline adject. phrase & (0) $\mathbf{0 \%}$ & (0) $\mathbf{0} \%$ & (0) $\mathbf{0} \%$ & (0) $\mathbf{0} \%$ & (1) $9 \%$ & (0) $\mathbf{0} \%$ & (1) $1 \%$ \\
\hline $\begin{array}{l}\text { prep. phrase, } \\
\text { adv. }\end{array}$ & (0) $0 \%$ & (0) $0 \%$ & (7) $24 \%$ & (0) $0 \%$ & (0) $\mathbf{0} \%$ & (2) $10 \%$ & (9) $12 \%$ \\
\hline total: $\mathbf{1 0 0} \%$ & (7) & (2) & (29) & (6) & (11) & (20) & (75) \\
\hline
\end{tabular}


(36) These people are not going to put up with me being out of control emotionally. (Times)

While in informal speech, both functions have a strong preference for the oblique ( 88 per cent of all gerundives in PP to $\mathrm{V}$ function and 96 per cent of those with object function take oblique case), this is not the case in formal discourse: in the Times corpus, it is only gerundives in object function which prefer the oblique (more precisely, 83 per cent of all gerundive nominals in object function). Gerundive nominalizations that figure in a PP following a verb have only a 57 per cent chance of taking the oblique: in 43 per cent of them, the possessive is used (as in (37)). Put differently, in formal language the genitive is more likely to occur in PP to V function (43 per cent) than it is in object function (17 per cent):

You have a rare disease which has resulted in your changing from a fit active farmer to, as you put it, "a housebound wreck" unable to do any physical work. (Times)

To conclude, certain correlations between the use of the genitive case and the function of the gerundive nominal can be identified-at least in formal language: in formal discourse, the chances that a possessive will occur in a gerundive nominalization with subject function, in a PP following a verb, as nominal postmodifier, and in a PP functioning as adjunct appear to be significantly higher than in informal speech, on the one hand, and than in gerundives functioning as object, as subject complement, or as PP following an adjective on the other.

\section{Oblique vs. Genitive: A Case of Lexical Diffusion}

We have thus far shown that two factors seem to influence the case which personal pronouns in gerundive nominalizations take: the register in which the nominalization is used, and the function which the nominal serves. It is, more particularly, only in specific functions and in formal language that the general preference for oblique case is less outspoken and the possessive case is used as well. In this section, we would like to make the point that, even if certain generalizations can be formulated with respect to the case of the personal pronoun in gerundive nominalizations in certain registers and functions, the behaviour of individual constructions (matrix verbs and prepositions) often remains unpredictable.

Consider first the behaviour of verbs that are semantically related and tend to be treated together in traditional grammars, such as stop and prevent, remember and forget. Even though stop and prevent, for instance, are grouped together in Jespersen's account of gerundive nominalizations ${ }^{27}$ and in Huddleston and Pullum's ${ }^{28}$ overview

\footnotetext{
${ }^{27}$ Jespersen, A Modern English Grammar, 148-9.

${ }^{28}$ Huddleston and Pullum, The Cambridge Grammar, 1238.
} 
of gerundive nominals in which the genitive is possible, the corpus shows them to behave quite differently with respect to the case of the personal pronoun that follows them: while the corpus does not contain a single instance of stop followed by a gerundive nominalization with possessive pronoun, it contains 32 instances of prevent followed by a possessive pronoun (of which four were found in the UKspoken and the Times corpora and 28 in the rest of the Cobuild corpus):

... the Yoruba ... are angry at the military Government which prevented his becoming President. (Times)

The injury is not expected to prevent his playing in the needle match against England ... (Times)

Huddleston and Pullum's remark that stop "is a questionable member" of the group of gerundives that take the genitive ${ }^{29}$ is thus confirmed by the analysis of gerundive nominals in the Cobuild corpus. However, why it is that stop does not take gerundive nominals with possessive determination, while prevent does, is unclear. Notice that the lack of -ing structures with possessive case after stop made us decide that there is no evidence that the structure following stop is a gerundive nominalization. Consequently, we did not to take stop into account for our study. Only diachronic research will be able to shed light on the question of whether stop has ever been used with the genitive case at all.

That important diachronic shifts from possessive to oblique may have taken place for some matrix verbs becomes clear when we consider prevent more closely: our data on prevent tie in nicely with Van Ek's (1966) counts, which were based on a corpus of texts of various kinds from 1950 to 1964. Together with those by Van Ek, our counts differ quite radically from those carried out in 1957 by Kirsten ${ }^{30}$ on the basis of a number of eighteenth- and nineteenth-century novels. Table 8 gives an overview of Kirsten's counts (first two rows) and those by Van Ek (third row), comparing them with our own tentative counts based on our analysis of the Cobuild data. In the first

Table 8 The diachronic evolution of the use of -ing forms after prevent

\begin{tabular}{|c|c|c|c|}
\hline & prevent + GEN + Ving & prevent $+O B L+$ Ving & prevent $+O B L+$ from Ving \\
\hline Kirsten 18th c & (25) $30 \%$ & (8) $10 \%$ & (49) $60 \%$ \\
\hline Kirsten 19th c & (48) $53 \%$ & (5) $6 \%$ & (37) $41 \%$ \\
\hline Van Ek 1950-1964 & (2) $5 \%$ & (14) $38 \%$ & (21) $57 \%$ \\
\hline Cobuild corpus & (32) $6 \%$ & (120) $23 \%$ & ) $71 \%$ \\
\hline
\end{tabular}

\footnotetext{
${ }^{29}$ See also Van Ek, Four Complementary Structures of Predication, 191.

${ }^{30}$ Van Ek, Four Complementary Structures of Predication, 191-2.
} 
column, the cases of prevent followed by a possessive pronoun are given ( $m y$, your, his, its, our, their); in the second column one finds the instances of gerundive nominals with oblique pronoun (me, you, him, it, us, them); and, finally, in the last column, the pattern prevent someone from doing something is given.

As is pointed out by Van $\mathrm{Ek}^{31}$ and Visser, ${ }^{32}$ the enormous decrease in the relative frequency of the possessive pronoun from the twentieth century onwards is especially noteworthy. Our Cobuild data - which span the time period of around 1990 up to the present-only confirm this decrease, with the possessive figuring in only 6 per cent of the -ing structures that follow prevent. More diachronic research is needed to find out whether stop has experienced a comparable shift.

Similar observations can be made about the use of gerundive nominals with remember and forget. Huddleston and Pullum ${ }^{33}$ classify them together and argue that they allow for both "genitive and non-genitive forms ... with the genitive as usual more formal." Once again, however, our analysis of the Cobuild data suggests that it is only remember that can still be construed with the genitive, while forget necessarily takes pronouns in the oblique case: in all, we found five instances of remember followed by a gerundive nominal with a possessive pronoun in the corpus, but none of forget:

(36) I don't remember their being so low before. (CB)

(37) Mr. Frier's son John ... remembers his telling stories ... (CB)

If it is true that remember and forget used to be possible with both the oblique and the genitive case, then our analysis of the corpus data suggests that they are evolving at different rates and that the shift towards the oblique has only been fully completed in gerundives following forget. Because the possessive remains possible after remember (in spite of the fact that the oblique case constitutes the unmarked option, with a total of 71 instances in the UKspoken and Times corpora only), remember has been included in our analysis.

A final observation, then, concerns structures that follow without, as in:

(38) Fred promised me he wouldn't let her go without me saying goodbye. (Times)

(39) Stephen Wall, his private secretary, had drafted an inaccurate letter without him realising this. (Times)

In modern grammars, ${ }^{34}$ without is typically compared to the use of with in adjuncts of contingency, ${ }^{35}$ as in:

\footnotetext{
${ }^{31}$ Van Ek, Four Complementary Structures of Predication, 192.

${ }^{32}$ Visser, An Historical Syntax, 2364.

${ }^{33}$ Huddleston and Pullum, The Cambridge Grammar, 1232.

${ }^{34}$ E.g. Quirk et al., A Comprehensive Grammar; Huddleston and Pullum, The Cambridge Grammar.

${ }^{35}$ Quirk et al., A Comprehensive Grammar, 629-30.
} 
(40) I had one or two situations but I suppose with me being a pretty big fellow if you jump on them straight away they quieten down. (UKspoken)

Huddleston and Pullum ${ }^{36}$ point out that after with and without "a gerund-participle in complement function cannot take a genitive subject." However, unlike with, which does not seem to allow for the genitive case, ${ }^{37}$ without does take the genitive case (as also pointed out in Jespersen ${ }^{38}$ ): we found four instances of without followed by a genitive in the Times corpus and the UKspoken corpus; and when we extended our query to the entire Cobuild corpus, we found another 30:

$$
\text { ... they're accessing things without your knowing it .... (UKspoken) }
$$

As far as case is concerned, therefore, our analysis of the Cobuild data shows that structures with with and without have to be distinguished. The reason why this is so and the implications for the status of the -ing structures following with and without will have to be looked at more closely in future research.

\section{Conclusion}

To conclude, the case which personal pronouns preceding the -ing form in gerundive nominalizations take correlates with the register in which the gerundive nominalization is used and with the function which the gerundive nominal serves in the clause. In some cases, it also turns out to depend on other, as yet imperfectly understood, factors. First, we have shown that the impact of register on gerundive nominalizations has often been simplified in the literature. In particular, we have argued that formal language cannot be said to prefer possessive case since the number of obliques in formal language is higher than that of possessives. Rather, our analysis of the Cobuild data has revealed that possessives prefer formal language: relatively more possessives are found in formal than in informal discourse. While it is therefore not correct to say that "the genitive is preferred if the item is a pronoun ... and the style is formal," 39 the corpus data which we extracted do confirm Huddleston and Pullum's ${ }^{40}$ observation that genitives "are more likely to occur in formal than in informal style."

By labelling the extracted gerundive nominals according to the function which they served in the clause, we found ourselves on the track of certain correlations between

\footnotetext{
${ }^{36}$ Huddleston and Pullum, The Cambridge Grammar, 461.

${ }^{37}$ The only case where with is followed by a gerundive nominalization with genitive pronoun is when it is part of a prepositional complement of a verb or of a nominal postmodifier:

a. ... it has primarily to do with their dragging their own self-esteem down by distorted negative thinking. (UKspoken)

b. Erm now then are you getting enough help with your shopping and preparing the meals and cleaning ... (UKspoken)

${ }^{38}$ Jespersen, A Modern English Grammar, 145.

${ }^{39}$ Quirk et al., A Comprehensive Grammar, 1063.

${ }^{40}$ Huddleston and Pullum, The Cambridge Grammar, 1192-3.
} 
the case of the pronominal determiner and the function of the nominal. Once again, register turned out to play a major role: in informal speech, all functions showed a strong preference for the oblique; in formal discourse, however, certain specific functions were shown to allow for the possessive more than others. Especially in gerundive nominals with subject function, the possessive turned out to constitute the preferred option. With respect to gerundive nominals functioning as object or as prepositional adjunct, finally, we touched briefly on the behaviour of a number of matrix verbs and prepositions which demonstrated the restrictions of making generalizations about case-function correlates and attested to the need for more research on word-specific contexts, synchronically as well as diachronically.

Importantly, not only has our analysis of the Cobuild data managed to shed light on a number of issues involved in gerundive nominalization, but we believe it has also pointed to many other issues that require further research. To name only a few: the normed frequency counts of gerundive nominals presented in (32) and (33) reveal that the number of gerundive nominals with pronominal determination is much higher in the UKspoken than in the Times corpus. Will these relative frequency counts be confirmed when other types of gerundive nominals are considered as well? Put differently, do we find significantly more gerundive nominals in informal than in formal language? And what about the relative frequency of oblique and possessive case in these types? As to the use of possessive case in gerundive nominals with specific functions, then: are there certain diachronic tendencies to be observed here? And why do gerundives following phrasal verbs turn out to opt for the genitive more frequently than do gerundive nominals in direct object function? Questions like these make it clear that what we have revealed about gerundive nominalization in this paper is only the tip of the iceberg. It will be interesting to see what is going on underwater.

\section{Acknowledgments}

The research reported on in this article builds on a paper which Hella Rogiers and Nadine Vermeylen wrote for the "English linguistics: Applied linguistics" course of Professor Kristin Davidse at the University of Leuven. Liesbet Heyvaert expanded the number of gerundive nominalizations to be analyzed (from 149 instances in Rogiers and Vermeylen's paper to 1,050 in this paper) and wrote up the article. Her work was funded by the Research Council of the University of Leuven (postdoctoral grant PDM/02/034). We are grateful to Kristin Davidse for discussing the analysis with us.

\section{References}

Biber, D., S. Conrad, and R. Reppen, Corpus Linguistics. Investigating Language Structure and Use. Cambridge: Cambridge University Press, 1998.

Declerck, Renaat. A Comprehensive Descriptive Grammar of English. Tokyo: Kaitakusha, 1991. 
Dekeyser, X., B. Devriendt, G. A. J. Tops, and S. Geukens. Foundations of English Grammar. 3rd edn. Antwerpen, Belgium: INKA, 1987.

Downing, Angela and Philip Locke. A University Course in English Grammar. New York: PrenticeHall, 1992.

Huddleston, Rodney, and Geoffrey K. Pullum. The Cambridge Grammar of the English Language. Cambridge: Cambridge University Press, 2002.

Jespersen, Otto. A Modern English Grammar on Historical Principles. Part IV. Syntax. London: George Allen \& Unwin, 1940.

Lees, Robert B. The Grammar of English Nominalizations. Bloomington, IN: University Research Center in Anthropology, Folklore and Linguistics, Publication 12, 1960/1968.

Meyer, Charles F. English Corpus Linguistics. An Introduction. Cambridge: Cambridge University Press, 2002.

Poutsma, H. A Grammar of Late Modern English. 2nd edn. Groningen, The Netherlands: Noordhoff, 1929.

Quirk, R., S. Greenbaum, G. Leech, and J. Svartvik. A Comprehensive Grammar of the English Language. London: Longman, 1985.

Schachter, Paul. "A nontransformational account of gerundive nominals in English." Linguistic Inquiry 7.2 (1976): 205-41.

Van Ek, J. A. Four Complementary Structures of Predication in Contemporary British English. An inventory. Groningen, The Netherlands: Wolters, 1966.

Visser, F. Th. An Historical Syntax of the English Language. Part 2. Syntactical Units with One Verb. Leiden, The Netherlands: E.J. Brill, 1972.

- An Historical Syntax of the English Language. Part 3, 2nd Half. Leiden, The Netherlands: E. J. Brill, 1973. 
Copyright of English Studies is the property of Taylor \& Francis Ltd. and its content may not be copied or emailed to multiple sites or posted to a listserv without the copyright holder's express written permission. However, users may print, download, or email articles for individual use. 